\title{
Effect of Rolling and Annealing on Microstructure and Mechanical Properties of High Purity Aluminum
}

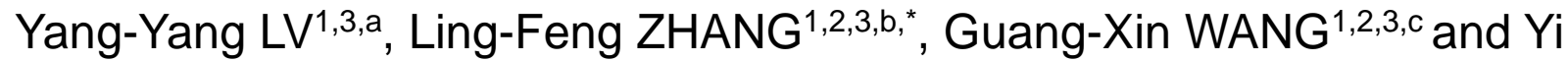 \\ $\mathrm{XIONG}^{1,2, \mathrm{~d}}$
}

\author{
${ }^{1}$ School of Materials Science and Engineering, Henan University of Science and Technology, \\ Luoyang 471023, China \\ ${ }^{2}$ Henan Collaborative Innovation Center of Non-ferrous Metals Generic Technology, Luoyang \\ 471023, China
}

${ }^{3}$ Research Center for High Purity Materials Henan University of Science ang Technology, Luoyang 471023, China

acl_Ivyang@163.com, bzh_lingfeng@163.com, 'cwgx58@126.com, dxy_hbdy@163.com

${ }^{*}$ Corresponding author

Keywords: High Purity Aluminum, Cold Rolling, Recrystallization, Microstructure, Mechanical Property.

\begin{abstract}
The high-purity aluminum with a purity of $5 \mathrm{~N} 5$ was cold-rolled with a cumulative deformation of $70 \%$, and the deformed high-purity aluminum was annealed at different temperatures and time. The microstructure and mechanical properties of deformed high purity aluminum and heat treatment were studied by means of microstructure analysis and mechanical property test.The results show that, after the cold deformation of $70 \% 5 \mathrm{~N} 5$ aluminum alloy, the work hardening is obvious, the tensile strength and microhardness are improved greatly, and the change trend after annealing is consistent, all with the increase of annealing temperature and the increase of holding time are gradually reduced. After annealing at $330{ }^{\circ} \mathrm{C} \times 20 \mathrm{~min}$, the microhardness decreased sharply, and the uniform fine equiaxed grains appeared, the occurrence of a complete recrystallization, more than the best annealing temperature and time after recrystallization, continue to increase the annealing temperature or increase the holding time will make recrystallized grains grow up, increasing the temperature high or increase the longer the insulation time, the more obvious the phenomenon of grain growth.
\end{abstract}

High purity aluminum has many excellent chemical and physical properties, such as high conductivity and thermal conductivity, low density, higher reflectivity of light and so on. Has a better performance than the primary aluminum in conductivity, reflectivity, ductility, and corrosion resistance. In the aerospace industry, the electronics industry and other fields have a very wide range of applications ${ }^{[1]}$. As a result of high purity aluminum and its good performance, it has been widely used in many areas, especially in the high-tech areas, has become an important material in today's society. But it also needs to meet certain performance indicators, such as the homogeneity of the microstructure, grain size, preferred orientation and so on $^{[2]}$. Therefore, it is necessary to make certain deformation and heat treatment of high purity aluminum in order to achieve the desired performance ${ }^{[3]}$. After the plastic deformation of high purity aluminum, and to recrystallize it can be obtained even fine grain ${ }^{[4]}$. At present, the domestic research on deformation and heat treatment of high pure aluminum is not enough, the purity is generally less than $5 \mathrm{~N}$, the $5 \mathrm{~N}$ and the purity of ultra pure aluminum was rarely reported ${ }^{[5-6]}$. And the deformation is generally between $40 \%-60 \%$, the high pure aluminum severe deformation is also rare ${ }^{[7-8]}$. Especially for the application of a wide range of high purity aluminum target, the grain size and uniformity requirements are high, the need for some of the processing of cast materials to meet the requirements ${ }^{[9]}$. In this paper, ultra-high purity aluminum with a purity of $5 \mathrm{~N} 5$ was studied by $70 \%$ severe cold-rolling deformation, and the effect of deep cold rolling and certain annealing process on the microstructure and properties of high purity aluminum was discussed. 


\section{The Experimental Materials and Methods}

The experimental material was segregated with high purity aluminum ingot with a purity of $5 \mathrm{~N} 5$. Cut into $50 \mathrm{~mm} \times 20 \mathrm{~mm} \times 20 \mathrm{~mm}$ rectangular box for cold rolling, rolling mill roll diameter $\Phi 450$ $\mathrm{mm}$ adjustable speed rolling mill. In order to prevent the rolling speed is too fast, the temperature is too high, after cooling and then the next pass, each rolling time to measure, the final control deformation of $70 \%$.

After the deformation of high purity aluminum cut into the appropriate size, and then into the low-temperature box resistance furnace annealing treatment. The annealing temperatures were $250^{\circ} \mathrm{C}, 300^{\circ} \mathrm{C}, 330^{\circ} \mathrm{C}$ and $350^{\circ} \mathrm{C}$, and the annealing time was $5 \mathrm{~min}, 10 \mathrm{~min}, 20 \mathrm{~min}$ and $30 \mathrm{~min}$. Respectively ${ }^{[10]}$. Then, the microstructure and mechanical properties of the samples were analyzed.

The hardness of the sample was measured by the HVS-1000A Vivtorinox microhardness tester. The load was $100 \mathrm{~g}$ and the loading time was $10 \mathrm{~s}$. In each sample surface, select the average of seven different points to test the hardness. After recording the data remove the maximum and minimum values of each sample, select the remaining five measurements to calculate the average. Then the tensile test was carried out on the UTM4104 electronic universal testing machine, the maximum test force of $10 \mathrm{kN}$, the accuracy level of 0.5 , the power of $0.75 \mathrm{~kW}$, the voltage is $220 \mathrm{~V}$. Tensile tests were carried out on specimens in different states. The metallographic corrosion of high purity aluminum is difficult ${ }^{[11]}$. In this paper, the etching process of high purity aluminum was carried out by using BUEHLER's ElectroMet electrolytic etching apparatus. The samples were first ground on sandpaper and subjected to electrolytic polishing in $800 \mathrm{ml}$ of ethanol $(95 \%), 60 \mathrm{ml}$ of perchloric acid (60\%) and $140 \mathrm{ml}$ of perchloric acid in distilled water. The voltage was about $40 \mathrm{~V}$ and the polishing time was $25 \mathrm{~S}$. And then chose the $16.8 \mathrm{~g} / \mathrm{L}$ of boric acid solution for anode coating. The voltage was about $25 \mathrm{~V}$, the current was about $0.3 \mathrm{~A}$, the coating time was $2 \mathrm{~min}$, and finally the metallographic observation was carried out in polarizing microscope ${ }^{[12-14]}$.

\section{Results and Analysis}

\subsection{Microstructure}

As shown in Figure 1, is $70 \%$ of the amount of rolling deformation and deformation after a different annealing process by 50 times the magnification of the microstructure. Figure 1 (a) is a $70 \%$ rolling deformation of the metallographic diagram, the grain is large, showing a significant deformation of the strip. Then, after the denaturation of the sample annealing, as shown in Figure 1 (b) and 1 (c), respectively, after $250^{\circ} \mathrm{C} \times 30 \mathrm{~min}$ and $300^{\circ} \mathrm{C} \times 30 \mathrm{~min}$ annealing process after the metallographic diagram, the grain size is still flattened. Indicating that the annealing deformation of $70 \%$, the annealing temperature of $300^{\circ} \mathrm{C}$ didn't reach the recrystallization temperature. 

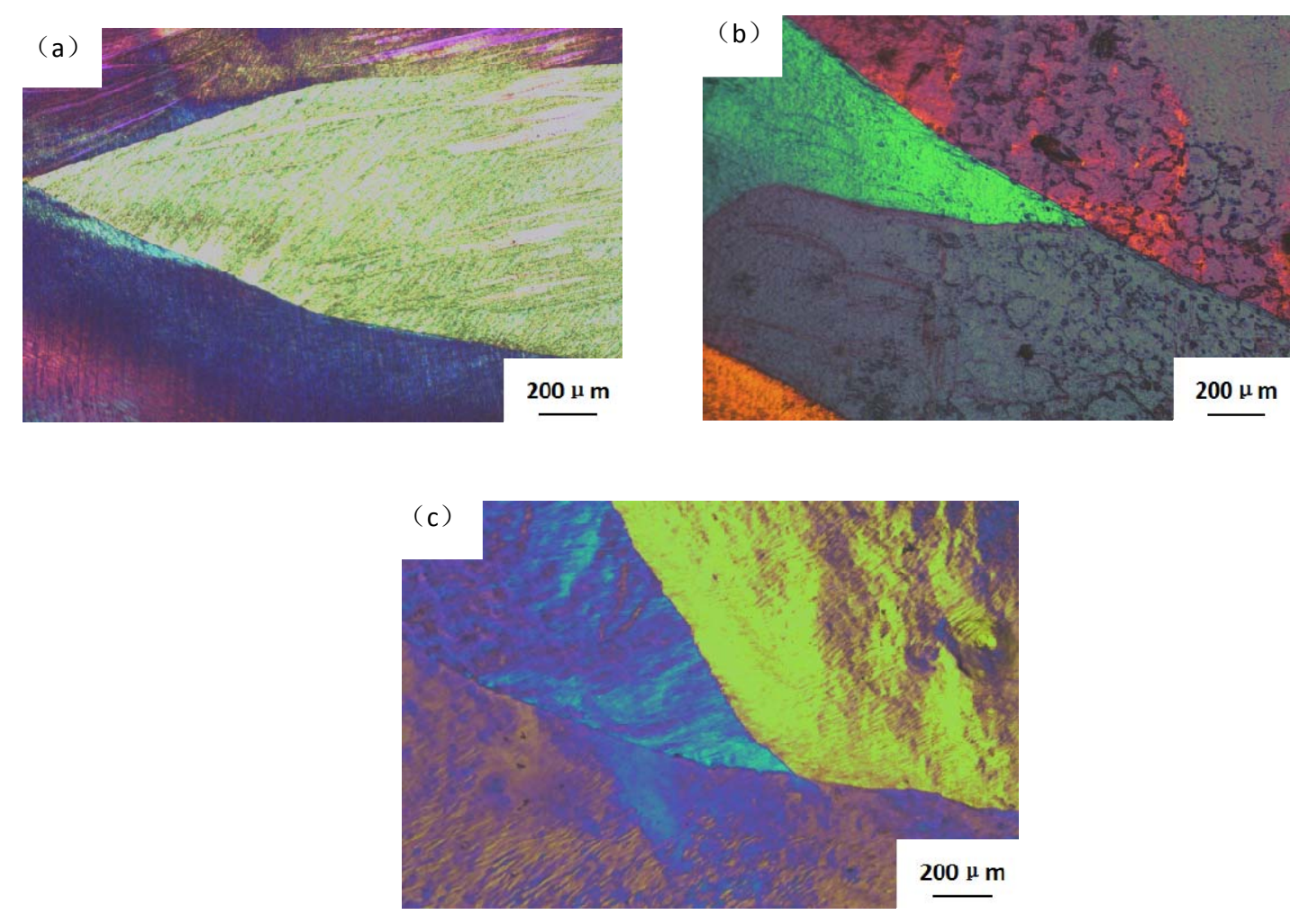

Fig. 1 Metallographic diagram of $70 \%$ rolling modified and annealed states (a) $70 \%$ rolled state; (b) $70 \%$ rolling, annealing at $250^{\circ} \mathrm{C} \times 30 \mathrm{~min}$; (c) $70 \%$ rolling, annealing at $300^{\circ} \mathrm{C} \times 30 \mathrm{~min}$

And then continue to increase the annealing temperature to $330^{\circ} \mathrm{C}$, as shown in Figure 2, is the magnified 50-times microstructure after $70 \%$ rolling deformation at $330^{\circ} \mathrm{C}$ annealing temperature of different annealing time. As shown in Figure 2 (a), after the annealing process at $330^{\circ} \mathrm{C} \times 5 \mathrm{~min}$, it can be seen that the grain is obviously reduced and becomes a uniform fibrous structure, which should be in the recovery stage. Continue to increase the holding time to $10 \mathrm{~min}$, such as 2 (b) the emergence of a new non-distorted grain core, and gradually grow into a new non-distorted grains, began to recrystallize phenomenon. When the holding time is increased to $20 \mathrm{~min}$, as shown in Figure 2 (c), the grains have been completely reorganized into undisturbed, uniformly refined equiaxed grains, and obtained the grain size of less than $200 \mu \mathrm{m}$, a complete recrystallization occurred. If we continue to increase the holding time, such as 2 (d), there is a phenomenon of grain growth driven by the surface energy. 

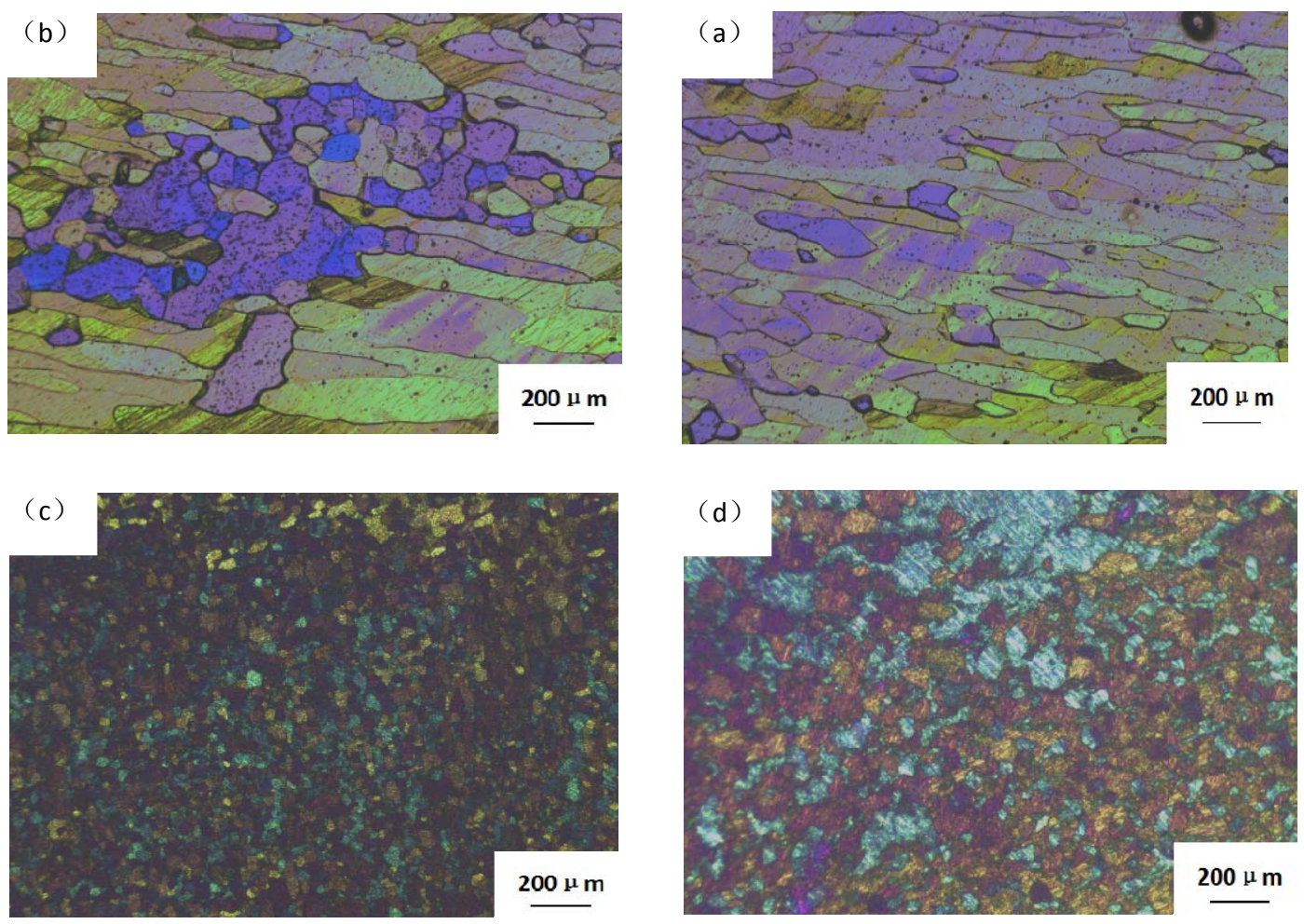

Fig. 2 Microstructure of different annealing time at annealing temperature of $330{ }^{\circ} \mathrm{C}$ (a) $5 \mathrm{~min}$; (b) $10 \mathrm{~min}$; (c) $20 \mathrm{~min}$; (d) $30 \mathrm{~min}$

When the annealing temperature is increased to $350^{\circ} \mathrm{C}$, as shown in Figure 3 , is the magnified 50-times microstructure at $350^{\circ} \mathrm{C}$ annealing temperature of different annealing time .Figure 3 (a) and 3 (b) are at $350{ }^{\circ} \mathrm{C}$ annealing temperature, respectively, after $10 \mathrm{~min}$ and $30 \mathrm{~min}$ holding time of the metallographic diagram, there is a clear phenomenon of grain growth, it is shown that when the sample reached the recrystallization annealing temperature and holding time, continuing to increase the recrystallization temperature or the increase of the holding time will make the recrystallization grains grow up and increasing the higher temperature or the longer holding time, grain growth is more obvious.
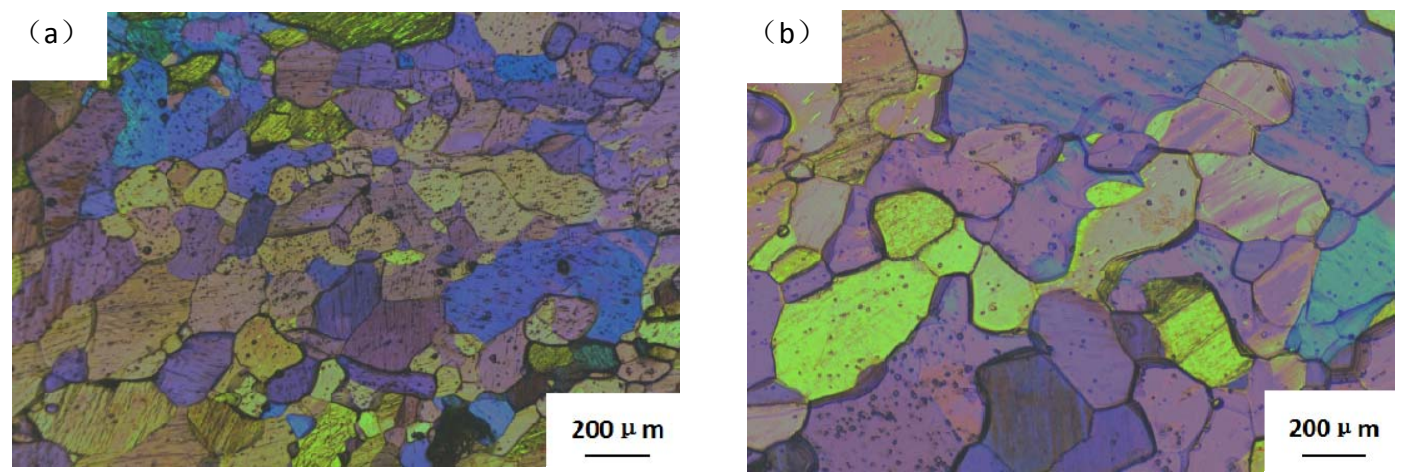

Fig. 3 Metallographic diagram after different holding time at $350^{\circ} \mathrm{C}$ annealing temperature

(a) $10 \mathrm{~min}$; (b) $30 \mathrm{~min}$

\subsection{Mechanical Properties}

The tensile test and the microhardness test were carried out on the samples with $70 \%$ rolling and annealed. The changes were as shown in Figs. 4 (a) and 4 (b), it can be seen that the trend of tensile strength and microhardness tend to be consistent. The hardness is $35.3 \mathrm{HV}$ in the rolling state, $46.5 \%$ higher than the original hardness $24.1 \mathrm{HV}$. The tensile strength increases from the original 
state of $18.5 \mathrm{MPa}$ to the rolling state $96 \mathrm{MPa}$, an increase of 4.1 times. The mechanical properties of the original state increased significantly, indicating significant hardening of the work. With the increase of temperature and the holding time, the microhardness and tensile strength gradually decrease, the internal tissue defects gradually disappear, and the dislocation density decreases gradually. In Fig. 4 (b), the microhardness and tensile strength of the material decreased sharply at the annealing time of $20 \mathrm{~min}$ at the annealing temperature of $330{ }^{\circ} \mathrm{C}$, indicating that the recrystallization occurred in this annealed state. Tissue defects and dislocation density are significantly reduced, and the results of the microstructure analysis of the material in this state are consistent.
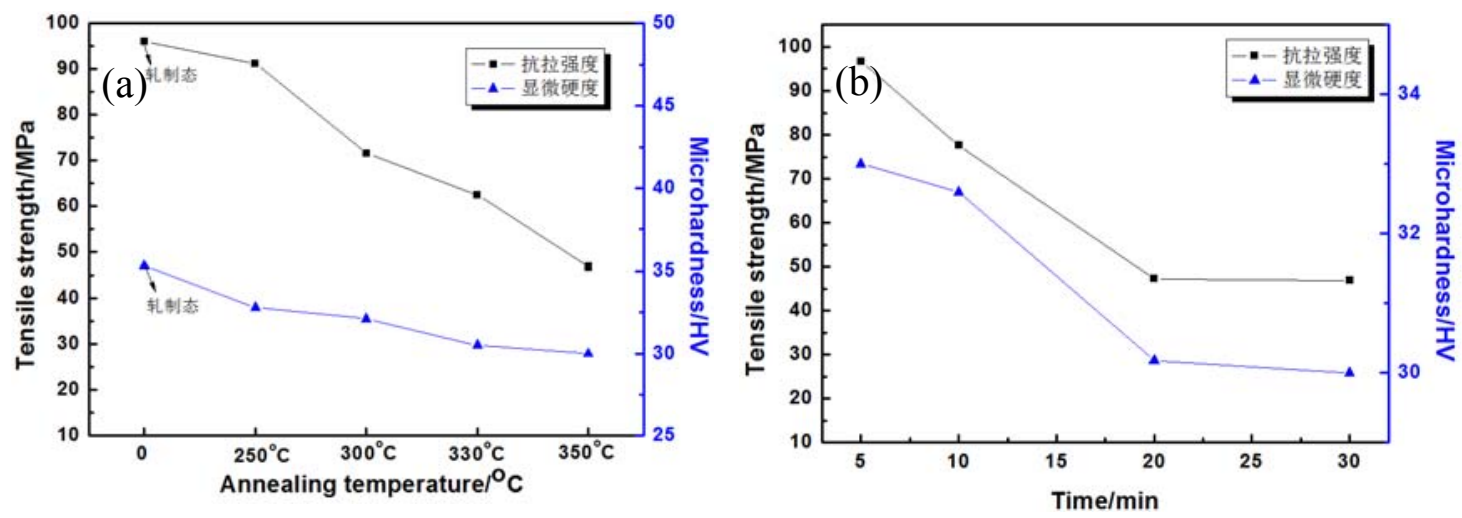

Fig. 4 Tensile strength and microhardness curves of $70 \%$ rolling high purity aluminum with different annealing temperatures and at annealing temperatures of $330^{\circ} \mathrm{C}$ with different holding time (a) Different temperatures; (b)Annealing at $330^{\circ} \mathrm{C}$ for different time

\section{Conclusion}

1) After the rolling of the high-purity aluminum material is $70 \%$, no dynamic recrystallization occurs, After annealing at $330{ }^{\circ} \mathrm{C}$ for $10 \mathrm{~min}$, the high purity aluminum deformation structure begin to recrystallize. When the holding time increases to $20 \mathrm{~min}$, the deformation of high purity aluminum is completely recrystallized and the grain is refined. With the increase of annealing temperature and the increase of holding time, the phenomenon of grain growth occurs, the higher the temperature, the longer the holding time, the more obvious the growing phenomenon.

2) The tensile strength and microhardness of the high purity aluminum material after deformation of $70 \%$ are greatly improved, the work hardening is obvious. After annealing, the trend of the two changes tend to be consistent, both with the increase of temperature and holding time, microhardness and tensile strength are gradually reduced.And after $330^{\circ} \mathrm{C} \times 20 \mathrm{~min}$ annealing process, the hardness decrease sharply, which is related to the recrystallization of the material.

3) The microstructure and mechanical properties of the samples show that the mechanical properties are improved obviously after $70 \%$ deformation of high purity aluminum. And the optimum annealing process is obtained at $330{ }^{\circ} \mathrm{C}$ for $20 \mathrm{~min}$, the complete recrystallization has been achieved, and the grain has been refined, which is improved in application performance.

\section{Acknowledgement}

This research was financially supported by the Henan Educational Committee (Key scientific research projects of Henan Province) No. 17A430017 and Henan University of Science and Technology Foundation for Innovative Capability-building Project No. $2014 Z C X 007$. 


\section{References}

[1] Zhu-Tang WANG, Talk about the purify aluminum, J. Metal World. 4 (2004) 36-37.

[2] Xue-Min YUAN, Advances in high-purity aluminum, J. Heilongjiang Metallurgy. 35, 1 (2015): $1-3$.

[3] Chang-Hee C, Jae-Han J, Chang-Seok O, et al, Room temperature recrystallization of 99.999 pct aluminum, J. Scripta Metallurgicaet Materialia. 30, 3 (1994) 325-330.

[4] Nian-Kui LI, Shu-Fen YE, Effect of homogenizing annealing on microstructure and properties of high-purity aluminum foil. Light Metal. 9 (1993) 50-54.

[5] Shu-Nong JIANG, Chu-Ming LIU, High-purity polycrystalline aluminum experimental study on dynamic recrystallization, J. Chang Sha, Central South University (2004).

[6] Yong-Jun CHEN, Qu-Dong WANG, Research development and prospect of severe plastic deformation for fine-grained material , J. Materials Review. 4, 19 (2005) 77-79.

[8] Jian Liu, Akhtar S. Khan, Raju Nambori, et al, Strain rate effect of high purity aluminum single crystals: Experiments and simulations, J. International Journal of Plasticity. 67 (2015) 39-52.

[9] Karantzalis A E,Lekatou A,Diavati E, Effect of destabilization heat treatments on the miceostructure of high-chromium cast iron, J. Journal of Materials Engineering and Peformance. 18, 8 (2009) 1078-1085.

[10] Qing-Feng ZHU, Ming-Hua CHEN, Chun-Yan BAN, et al, Effect of annealing temperature on high purity aluminum deformation organization, J. Heat Treatment of Metals. 36, 6 (2011) 171-114.

[11] Wetseher F, Vorhauer A, Pippan R, Strain hardening during higll pressure torsion deformation, J. Mater. Sci. Eng. A. 41, 1 (2005) 213-216.

[12] Chen M C, Hsieh $\mathrm{H} \mathrm{C}$, Wu W T, The evolution of microstructures and mechanical properties during accumulative roll bondin of A1/Mg composite, J. Alloys Compd. 41, 6 (2006)169-174.

[13] Na LIU, Multi-directional impact forging and rolling process for high purity aluminum Structure and Properties, D. Northeastern university (2011).

[14] Yi XIONG, Tian-Tian HE, Zhi-Qiang GUO, et al, Effects of different temperatures and severe deformation and annealing of the aluminum industry organizations, J. Journal of Material Heat Treatment. 32, 9 (2011) 63-66. 